\title{
Abscisic acid phytohormone estimation in tubers and shoots of Ipomoea batatas subjected to long drought stress using competitive immunological assay
}

\author{
Carla S. S. Gouveia ${ }^{a, *}$, (D) José F. T. Ganança ${ }^{a}$, Jan J. Slaski ${ }^{a, b}$, Vincent Lebot ${ }^{c}$ and \\ Miguel Â. A. Pinheiro de Carvalho ${ }^{a}$ \\ aISOPlexis Genebank, Faculty of Life Sciences, University of Madeira, Funchal, Madeira, 9020-105, Portugal \\ ${ }^{\mathrm{b}}$ Ecosystems and Plant Sciences, InnoTech Alberta, Vegreville, Alberta, Canada \\ ${ }^{c}$ CIRAD-BIOS, PO Box 946, Port Vila, Vanuatu
}

\author{
Correspondence \\ *Corresponding author, \\ e-mail: csgouveia@staff.uma.pt \\ Received 19 May 2020; \\ revised 3 August 2020
}

doi:10.1111/ppl.13192
Sweet potato (Ipomoea batatas L.), typically cultivated in temperate climates under low inputs, is one of the most important crops worldwide. Abscisic acid (ABA) is an important plant stress-induced phytohormone. Hitherto, few works analyzed the ABA function in sweet potato tissue growth. Very scarce information is available concerning the $A B A$ role in sweet potato response to water scarcity conditions. Here, we show the ABA content variation in shoots and tubers of eight sweet potato accessions subjected to drought stress. ABA was also related to other resistance traits, such as chlorophyll content index $(\mathrm{CCl})$, carbon isotopic discrimination $\left(\Delta^{13} \mathrm{C}\right)$, oxalic acid (OA) and water use efficiency (WUE), to assess stress response mechanisms to water deficit between their organs. The most resilient droughtstressed sweet potato plants accumulated ABA-shoot, and significantly decreased the $\mathrm{ABA}$-tuber content. $\mathrm{ABA}$ signaling was related to $\Delta^{13} \mathrm{C}$ and $\mathrm{CCl}$ decrease and WUE increment, as an attempt to cope with water stress by partially closing the stomata. The partial closure of stomata could be in part due to the presence of OA-shoots, known to affect the intensity of the ABA-shoot signal in stomatal closure. Higher $\mathrm{CCl}$ content and minimal $\Delta^{13} \mathrm{C}$-shoot differences indicated good carboxylation fractionation, with higher $\Delta^{13} \mathrm{C}$-tuber content as an indicator of efficient tuber ${ }^{13} \mathrm{C}$ fixation and growth. Our work demonstrated that ABA could be used in conjunction with the other traits studied for the assessment of sweet potato whole-plant responses to environmental stresses, and thus aid the selection of the best drought tolerant genotypes for breeding programs.

\section{Introduction}

Sweet potato [/pomoea batatas (L.) Lam.], after potatoes (Solanum tuberosum L.) and cassava (Manihot esculenta Crantz) root tubers, is one of the most important staple crops in the world (Lebot 2009, FAOSTAT Statistical
Database 2018). Sweet potato is an important food source supply in tropical and developing countries owing to the storage of $80-90 \%$ carbohydrates in root dry matter content (Lebot 2009). Some countries also use the sweet potato leaves as a vegetable source, providing high

Abbreviations $-\delta^{13} \mathrm{C}$, carbon isotope composition; $\Delta^{13} \mathrm{C}$, carbon isotope discrimination; $\mathrm{ABA}$, abscisic acid; Acc., accession; CAN, Canary Islands; CCl, chlorophyll content index; ELISA, enzyme-linked immunosorbent assay; GUI, Guinea-Bissau; HRP, Horseradish Peroxidase; MAD, Madeira Island; OA, oxalic acid; PAR, photosynthetic active radiation; PCA, principal component analysis; $\mathrm{RH}_{\mathrm{a}}$, relative air humidity; $\mathrm{VWC}$, volume water content of soil; WUE, water use efficiency. 
content in protein, soluble dietary fiber, minerals (iron), polyphenols and vitamins (Bradbury and Holloway 1988, Ishida et al. 2000).

The major sweet potato production occurs in Asia, with 60.7 Mt in 2018, representing $66 \%$ of worldwide production (FAOSTAT Statistical Database 2018). Its production is usually done in temperate climates, under low input conditions. With the characteristic low plant growth habit and extensive root system, the sweet potato can be moderately tolerant to water scarcity (Smittle et al. 1990, Ekanayake and Collins 2004, Motsa et al. 2015a, 2015b). The exposure to an extended period of abiotic stress leads to plant physiological modifications, changing the crop quality and biochemical composition to cope and survive stress (Wang and Frei 2011).

Abscisic acid (ABA) is an important isoprenoid stressinduced phytohormone present in sweet potato (Nakatani and Komeichi 1991, Nagata and Saitou 2009, Wani et al. 2016, Lau et al. 2018). This isoprenoid plays a pivotal role in numerous plant biochemical and physiological processes, including stomatal closure, lipid synthesis, protein storage and starch accumulation, related to development, growth and signaling pathways (Mengel et al. 2001, Firon et al. 2009, Danquah et al. 2013, Wani et al. 2016, Saddhe et al. 2017, Vishwakarma et al. 2017). Proline and ethylene synthesis, which have a protective function under both water and saline stress, are also stimulated by ABA (Mengel et al. 2001). ABA is considered one of the most effective plant hormones due to its quick synthesis under abiotic stresses, such as drought, salinity, temperature and nutrient imbalance (Mengel et al. 2001, Firon et al. 2009, Osakabe et al. 2014, Sah et al. 2016, Salehi-Lisar and Bakhshayeshan-Agdam 2016). Plants also abscises organs, such as leaf abscission, to promote senescence as stress response (Mengel et al. 2001, Sah et al. 2016). ABA can be quantitated by the Enzyme-Linked Immunosorbent Assay (ELISA), a sensitive method that can detect low concentrations of this phytohormone in plant tissues. Currently, it is one of the most affordable techniques that allow fast detection of ABA without the need for complex purification steps and uses a combination of the specificity of antigen-antibody reaction with the same sensitivity of enzymatic assays (Huang et al. 2014).

Under a tenacious dry environment, root ABA signalizes the plant shoots that they are facing stressful conditions around the roots, leading to stomatal closure to avoid water loss (Wani et al. 2016). Drought could induce the stomatal closure through a root-to-shoot signaling with an $A B A$ synthesis occurring mainly in the chloroplasts (Mengel et al. 2001, Osakabe et al. 2014, Salehi-Lisar and Bakhshayeshan-Agdam 2016). Other works also indicate that the leaves are the predominant location for ABA biosynthesis during drought stress, and also that the ABA from leaves has a greater effect over root development (McAdam et al. 2016). The cellular dehydration that triggers ABA biosynthesis in the chloroplast mesophyll tissues involves various enzymes and the utilization of $\beta$-carotene (Mengel et al. 2001, Wani et al. 2016, Vishwakarma et al. 2017). The stomatal responses are closely related to soil water potential, with its closure inhibiting transpiration and increasing the water flow in the plant through hydraulic conductivity (Mengel et al. 2001, Ma and Qin 2014, Osakabe et al. 2014, Salehi-Lisar and BakhshayeshanAgdam 2016). The plasma membrane and tonoplast use the ion and water transport systems to control turgor pressure changes in the guard cell. The guard cells detect the increase of $\mathrm{ABA}$ levels, leading to a subsequent reduction of turgor and volume to avoid water loss, and trigger the stomatal closure (Ma and Qin 2014, Osakabe et al. 2014).

The atmospheric $\mathrm{CO}_{2}$ also acts as a signaling molecule in stomatal responses, whereas increased $\mathrm{CO}_{2}$ concentrations in leaves induce the stomatal closure, leading to a reduction in the photosynthesis rate in leaves, and affecting the water use efficiency (WUE; Salehi-Lisar and Bakhshayeshan-Agdam 2016, Osakabe et al. 2014). WUE reflects how plants manage the water use for vital activities and plant production during scarcity conditions, with the most tolerant ones usually displaying higher WUE (Mengel et al. 2001, Ganança et al. 2018, Gouveia et al. 2019). The chlorophyll measured in the full-grown leaves could be associated with the rate of photosynthesis, which is one of the most common parameters used as indicator of plant performance under drought stress (Shao et al. 2015, Salehi-Lisar and Bakhshayeshan-Agdam 2016, Gouveia et al. 2020). The carbon isotopic discrimination $\left(\Delta^{13} \mathrm{C}\right)$, that represents the photosynthetic depletion of ${ }^{13} \mathrm{C}$ in field-grown plants, is linked with stomatal aperture and is commonly used in C3 plants for the assessment of drought resilience (Farquhar et al. 1989, Zhang et al. 2015, Gouveia et al. 2019). Oxalic acid (OA) is an ethanedioic acid that inhibits ABA-induced stomatal closure in Arabidopsis thaliana plants (Guimarães and Stotz 2004). OA is a free acid that can form an equilibrium between soluble (potassium or sodium oxalate) or insoluble (calcium oxalate) salts, which variation plays an important role in the plant ion balance and osmoregulation under drought conditions (Franceschi and Horner 1980, Gouveia et al. 2020).

The chlorophyll content index $(\mathrm{CCl}), \Delta^{13} \mathrm{C}, \mathrm{OA}$ and WUE traits were previously used in the evaluation of the crop resilience to water scarcity environments (Gouveia et al. 2019, Gouveia et al. 2020). To date, a few works reported the ABA effects on sweet potato cultivars, including tuber yield of two accessions grown in fully irrigated pots (Nakatani and Komeichi 1991), the 
inhibitory growth effects of exogenous application of $A B A$ to in vitro plantlets of one accession (Jarret and Gawel 1991), sink activity through leaf-petiole cuttings from one accession grown in a growth chamber and treated with ABA solution (Nagata and Saitou 2009), and growth of in vitro shoots of two accessions exposed to osmotic pressure induced by polyethylene glycol (Lau et al. 2018). These experiments revealed that ABA was one of the factors that regulated the sweet potato sink activity and strength. The higher the sink activity, the higher sugar uptake and metabolic activity observed in the growing tuberous roots (Nagata and Saitou 2009). The thickening of the tuberous root diameter by cell division activity in the secondary cambium of sweet potato was mainly promoted by ABA located around the primary cambium and meristem in the xylem (Nagata and Saitou 2009, Ravi and Saravanan 2012). The heaviest tubers that show the highest $\mathrm{ABA}$ content under control conditions had a decreased tissue growth under osmotic pressure (Nakatani and Komeichi 1991, Nagata and Saitou 2009, Lau et al. 2018). These experiments were performed on a model scale to assess ABA importance in the growth of sweet potato plantlets without involving the real field conditions, and determining ABA throughout the whole plant subjected to water stress. Therefore, our study aimed to better elucidate the ABA involvement in the responses of field full-grown sweet potatoes subjected to long water scarcity conditions. We used a set of eight accessions from diverse geographical provenances to seek if drought leads to endogenous ABA accumulation due to stress as a physiological response to drought stress conditions. The specific goals were: (1) determining the ABA content in shoots and tubers of field-grown sweet potato plants subjected to long-term drought stress, and (2) relating ABA with other resistance traits $\left(\mathrm{CCl}, \Delta^{13} \mathrm{C}\right.$, OA and WUE) evolved in crop tolerance to better understand the sweet potato responses to water deficit.

\section{Materials and methods}

\section{Sweet potato accessions}

Eight accessions of sweet potato [I. batatas (L.) Lam.] from Madeira Island (MAD), Canary Islands (CAN) and Guinea-Bissau (GUI) (Table 1) were submitted to water scarcity conditions in the present study.

\section{Experimental field assay}

Five months of field trials were established in 2017 at the ISOPlexis experimental field $\left(32^{\circ} 39^{\prime} \mathrm{N}, 16^{\circ} 55^{\prime} \mathrm{W}\right.$, at Funchal, Madeira, Portugal), using a split-plot design. In the main plot, the sweet potato accessions were grown in
Table 1. Identification code, variety name and origin of eight sweet potato (Ipomoea batatas L.) accessions subjected to water scarcity conditions. Each accession has an identification number code used by the ISOPlexis Genebank.

\begin{tabular}{lll}
\hline Accession ID & Variety local name & \multicolumn{1}{c}{ Origin } \\
\hline 1036 & Brasileira & Madeira Island (MAD) \\
1038 & 5 Bicos & Madeira Island (MAD) \\
2927 & de Flor & Madeira Island (MAD) \\
3126 & Inglesa & Madeira Island (MAD) \\
2937 & Roja & Canary Islands - Tenerife (CAN) \\
2938 & Cubana & Canary Islands - Tenerife (CAN) \\
3124 & Vermelha & Guinea-Bissau - Bafatá (GUI) \\
3125 & Branca & Guinea-Bissau - Bafatá (GUI) \\
\hline
\end{tabular}

two independent blocks, one under regular open field conditions (control) and the other under an open rain shelter (experimental variant). The shelter aimed to avoid rain feed and ensure the water deficit conditions. Each accession was planted in three subplots (replicates): eight independent rows per block, 30 vine cuttings per accession in total, with $70 \times 80 \mathrm{~cm}$ in and between the rows. This makes five vine cuttings per accession, added in each row per subplot, that were fully irrigated in both open and shelter environments until the beginning of the third month of the trial. Three vines were also added as test samples, in both open and shelter blocks, exempt from water stress throughout the trial duration by keeping full irrigation. Two distinct water regimes were then applied, through drip irrigation system, with $1.6 \mathrm{~mm}$ for control and $0.9 \mathrm{~mm}$ for water deficit variants, per subplot, three times a week during the remaining 3 months. During this period, control block received approximately $77 \mathrm{~mm}$ of water, while the drought block received approximately $54 \mathrm{~mm}$. Controls were also fed with $117.5 \mathrm{~mm}$ of rainfall during this period. During rain periods, irrigation was suspended on control block. Both control and drought variants were also assessed periodically for the photosynthetic active radiation (PAR, 400-700 nm) with a ceptometer (AccuPAR LP-80), volume water content of soil $\left(\mathrm{VWC}_{\mathrm{s}}\right)$ with a soil moisture sensor (WaterScout SM10), air temperature $\left(\mathrm{T}_{\mathrm{a}}\right)$ and relative air humidity $\left(\mathrm{RH}_{\mathrm{a}}\right)$ with a data logger (Testo $\left.174 \mathrm{H}\right)$. During the assay, we registered a $24.6 \%$ PAR decrease under the rain shelter relative to open field environment, on average, with $1514.5 \mu \mathrm{mol} \mathrm{m}{ }^{-2} \mathrm{~s}^{-1}$ for control and $1142.0 \mu \mathrm{mol} \mathrm{m}{ }^{-2} \mathrm{~s}^{-1}$ for drought. The $\mathrm{VWC}_{\mathrm{s}}$ measured at $10 \mathrm{~cm}$ of depth of homogenized field soil shown on average $12.8 \% \mathrm{VWC}_{\mathrm{s}}$ for control, representing $35 \%$ of field capacity, and $3.5 \% \mathrm{VWC}_{\mathrm{s}}$ for drought, representing equal or less than $10 \%$ of field capacity. During the assay, an average of $19.46^{\circ} \mathrm{C} \mathrm{T}_{\mathrm{a}}$ and $68.07 \% \mathrm{RH}_{\mathrm{a}}$ were observed for control; an average $22.25^{\circ} \mathrm{C} \mathrm{T}_{a}$ and $66.40 \% \mathrm{RH}_{\mathrm{a}}$ were registered for drought. Throughout 
the entire agronomic trial, neither fertilizers nor pesticides were applied, and manual weeding was performed regularly.

\section{Preparation of sweet potatoes whole-plant flour samples}

At the end of the agronomic trial, 384 root tubers and shoots (stem, stalk and leaves) samples from control and drought plots were collected. All samples were washed, weighed (Sartorius Basic BA2100S), chopped on a mandolin cutter (2-3 $\mathrm{mm}$ thick), subsequently placed in an air oven to dehydrate until constant weight during approximately $48 \mathrm{~h}$ at $65^{\circ} \mathrm{C}$ (Memmert UF260), and finally ground into flour (IKA-Werke M20). The flour was placed in bags (Termofilm PA/PE), vacuum sealed (Audionvac VMS153) and stored at $-35^{\circ} \mathrm{C}$ (Liebherr ProfiLine GGPV6570) until analysis.

\section{Quantitative detection of abscisic acid in plant tissues}

$\mathrm{ABA}$, a weak acid, is a sesquiterpene with an $\alpha, \beta$-unsaturated ketone in the ring and a conjugated diene side chain (Huang et al. 2014). Its content was determined in the root tuber and shoot flours by the ELISA technique, using the ABA ELISA Kit (MBS 282218, 96 tests, MyBioSource Inc.) and a microplate reader (Tecan Sunrise Remote A-5082; software Magellan ${ }^{\mathrm{TM}}$ V7.1, Tecan). Flour samples were previously extracted with $0.940 \mu \mathrm{l} 1 \times \mathrm{PBS}$, and centrifuged at $9838 \mathrm{~g}$ during 5 min, with supernatant collected for analysis. Lyophilized ABA standard was diluted (from 1.56 to $100 \mathrm{ng} \mathrm{ml}^{-1}$ ) and used as calibration standards. Specifically, $50 \mu \mathrm{l}$ of standards and samples were individually added to the microplate wells pre-coated with an antibody specific to $A B A$, followed by $50 \mu \mathrm{l}$ Horseradish Peroxidase (HRP)-conjugated $\mathrm{ABA}$, and incubated for $1 \mathrm{~h}$ at $37^{\circ} \mathrm{C}$, protected from light. The competitive inhibition reaction occurs between HRP-labeled $\mathrm{ABA}$ and unlabeled $A B A$ with the antibody. One hundred microliter of substrate solution was added to the wells protected from light and incubated for $20 \mathrm{~min}$ at $37^{\circ} \mathrm{C}$. The reaction was terminated by adding $50 \mu \mathrm{l}$ of stop solution. The obtained data at $450 \mathrm{~nm}$, corrected at $620 \mathrm{~nm}$, were subjected to logarithmic transformations. The analyses were performed in triplicate and the values were expressed in ng g ${ }^{-1}$ of dry flour.

The method accuracy was validated through the recovery index percentage of ABA (Van Reeuwijk et al. 1998). Three distinct flour samples were spiked with $25 \mathrm{ng} \mathrm{ml}^{-1}$. The samples and the spikes were analyzed five times, showing $102 \%$ of recovery index, a high sensitivity and excellent specificity for $\mathrm{ABA}$ detection and quantification in sweet potato tissues.

\section{Carbon isotope discrimination}

The sweet potato root tuber and shoot flours were vacuum packaged and sent to the Natural Resources Analytical Laboratory at the University of Alberta (Edmonton, Canada) for carbon isotope composition $\left(\delta^{13} \mathrm{C}\right)$ analysis (Gouveia et al. 2019). The $\delta^{13} \mathrm{C}$ was determined by the micro-chemical AOAC 972.43:2000 method, using a Delta $\vee$ Advantage Continuous Flow Isotope Ratio Mass Spectrometer (Thermo Finnigan Corp CF-IRMS). The $\delta^{13} \mathrm{C}$ was converted into $\Delta^{13} \mathrm{C}$, from the obtained carbon isotope composition of plant material $\left(\delta^{13} \mathrm{C}_{\mathrm{p}}\right)$ and the source of atmospheric $\mathrm{CO}_{2}$ carbon $\left(\delta^{13} \mathrm{C}_{\mathrm{a}}=-8 \%\right)$, according to Farquhar et al. (1989) equation:

$$
\Delta^{13} \mathrm{C}(\%)=\left(\delta^{13} \mathrm{C}_{\mathrm{a}}-\delta^{13} \mathrm{C}_{\mathrm{p}}\right) /\left(1+\delta^{13} \mathrm{C}_{\mathrm{p}}\right)
$$

The analysis was made in triplicate with results presented in \% units of dry flour.

\section{Chlorophyll content index}

The relative chlorophyll content of the sweet potato fresh leaves was measured and expressed as the CCI. We employed a non-destructive measurement method using a chlorophyll content meter (Opti-Sciences CCM-200 PLUS). The $\mathrm{CCl}$ values were obtained through the absorbance in transmittance mode, at 653 and $931 \mathrm{~nm}$, whose values were proportional to the amount of chlorophyll in the tissue. Three measurements were performed in the morning on the adaxial leaf surface, avoiding the branching veins. An average $\mathrm{CCl}$ value was recorded for each replicate.

\section{Oxalic acid}

OA was quantitated in flour samples from root tubers and shoots (Gouveia et al. 2020). Exactly $0.4 \mathrm{~g}$ of flour was extracted with hydrochloric acid $(\mathrm{HCl}, 6.0 \mathrm{M})$ to allow the reduction of oxalic into glyoxylic acid, with a further reduction into glycolic acid. A potassium permanganate solution $\left(\mathrm{KMnO}_{4}, 0.05 \mathrm{M}\right)$ was used to precipitate and titrate the sample extracts for OA quantitation. We used Dye (1956) calculation for the total OA quantification. The analyses were made in triplicate, with values

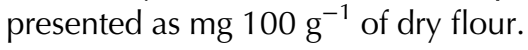

\section{Water use efficiency}

WUE was calculated as the ratio of the whole-plant dehydrated biomass to total water used per subplot and expressed in $\mathrm{g} \mathrm{I}^{-1}$ (Ganança et al. 2018). 


\section{Statistical methods}

The results were expressed on a dry weight basis, as the main average of sweet potato root tubers and shoots, for control vs. drought plots. IBM sPSS Statistics V24 for Mac was used for one-way ANOVA, Tukey HSD test and Pearson correlations. The statistically significant differences were expressed with $P$-value lower than 0.05. The MVSP V3.1 for Windows was used to perform the principal component analysis (PCA).

\section{Results}

\section{$A B A$ variation in root tubers and shoots during drought}

A wide range of strategies of $A B A$ synthesis and accumulation in both organs was observed among the eight sweet potato accessions. The data of $\mathrm{ABA}$ variation in root tubers and shoots for both control and drought experimental variants are shown in Table 2.

Overall, the ABA mean content in the shoots was almost 5 -fold higher than in the tubers for control and reached almost 11 folds under drought. At the same time, the ABA mean content decreased by $37 \%$ in the tubers, from 45 to $28 \mathrm{ng} \mathrm{g}^{-1}$, meanwhile it increased by $41 \%$ in the shoots, from 215 to $304 \mathrm{ng} \mathrm{g}^{-1}$, under water scarcity.

The variation of ABA-shoot content submitted to drought ranged from 175.1 (acc. 3125) to $483.5 \mathrm{ng} \mathrm{g}^{-1}$ (acc. 1036). The variations of ABA-tuber content were between 11.5 (acc. 1038) and $50.5 \mathrm{ng} \mathrm{g}^{-1}$ (acc. 3125). The highest values of $A B A$ content were recorded in the shoots, but the highest variations were observed in the tubers, with 4.4-folds (drought) and 16.9-folds (control), respectively.

The analysis of $A B A$ variation in tubers shows that acc. 3125 holds a significant highest content under both control and stress variants, decreasing during stress from 98 to $51 \mathrm{ng} \mathrm{g}^{-1}(-48 \%)$. However, the highest decrease was observed in the acc. 1038, where ABA-tuber content changes from 59 to $12 \mathrm{ng} \mathrm{g}^{-1}$ (-80\%) under stress. That is, under stress, the ABA content varied according to the following series: acc. $3125\left(-48 \mathrm{ng} \mathrm{g}^{-1}\right), 1038\left(-47 \mathrm{ng} \mathrm{g}^{-1}\right)$, $2938\left(-29 \mathrm{ng} \mathrm{g}^{-1}\right), 1036\left(-12 \mathrm{ng} \mathrm{g}^{-1}\right), 2937\left(-9 \mathrm{ng} \mathrm{g}^{-1}\right)$, $3126\left(-9 \mathrm{ng} \mathrm{g}^{-1}\right)$, with acc. $2927\left(+8 \mathrm{ng} \mathrm{g}^{-1}\right)$ and 3124 $\left(+15 \mathrm{ng} \mathrm{g}^{-1}\right)$ as exceptions. These last two accessions had the lowest ABA-tuber content in control conditions, but were the only ones that recorded an $\mathrm{ABA}$ increase when submitted to drought, from 6 to $14 \mathrm{ng} \mathrm{g}^{-1}$ (133\%), and 7 to $22 \mathrm{ng} \mathrm{g}^{-1}(214 \%)$, respectively.

Still, in the shoots, the acc. 1036 had significantly the highest variation of $\mathrm{ABA}$ content between control and stress conditions, increasing from 298 to $484 \mathrm{ng} \mathrm{g}^{-1}$ $(+62 \%)$. Meanwhile, the ABA-shoot suffers the lowest variation in acc. 3124, only ranging from 288 to $295 \mathrm{ng} \mathrm{g}^{-1}(+2 \%)$. Contrariwise, acc. 3125 showed the lowest ABA-shoot content under stress, with $175 \mathrm{ng} \mathrm{g}^{-1}$. The ABA variation in shoots, due to stress, increased according to the following series: acc. $3124\left(+7.8 \mathrm{ng} \mathrm{g}^{-1}\right)$, $3125\left(+42.6 \quad \mathrm{ng} \mathrm{g}^{-1}\right), 2937 \quad\left(+46.8 \quad \mathrm{ng} \mathrm{g}^{-1}\right), \quad 1038$ $\left(+59.5 \mathrm{ng} \mathrm{g}^{-1}\right), 2937\left(+71.9 \mathrm{ng} \mathrm{g}^{-1}\right), 3126\left(+145.0 \mathrm{ng} \mathrm{g}^{-1}\right)$, $2938\left(+153.6 \mathrm{ng} \mathrm{g}^{-1}\right)$ and $1036\left(+185.7 \mathrm{ng} \mathrm{g}^{-1}\right)$.

\section{$\Delta{ }^{13} \mathrm{C}$ and $\mathrm{OA}$ in root tubers and shoots during drought}

Table 2 shows the variation of carbon isotope discrimination $\left(\Delta^{13} \mathrm{C}\right)$ and $\mathrm{OA}$ content in the control and experimental (stress) variants.

Water scarcity slightly decreased the $\Delta^{13} \mathrm{C}$ content in both organs. On average, drought decreased $\Delta^{13} \mathrm{C}$-shoot from 20 to $18 \%$ o $(-10.0 \%)$, while the $\Delta^{13} \mathrm{C}$-tuber decreased from 18 to $17 \%$ ( $(-6 \%)$. The acc. 3124 was the exception, by slightly increasing the $\Delta^{13} \mathrm{C}$-shoot during drought, but remaining at $20 \%$ under both experimental conditions. However, acc. 1036 had the highest $\Delta{ }^{13} \mathrm{C}$-tuber content but also exhibited the highest loss due to drought, ranging from 19 to $17 \%$ o $(-11 \%)$. Conversely, both the acc. 1038 and 3124 showed the lowest difference and significantly higher $\Delta^{13} \mathrm{C}$ content in both organs under both experimental conditions. The acc. 3126 showed the lowest $\Delta^{13} \mathrm{C}$ content in both organs under drought stress, displaying $15 \%$ for $\Delta{ }^{13} \mathrm{C}$-tuber and $16 \%$ for $\Delta^{13} \mathrm{C}$-shoot.

The OA content in shoots was about threefold higher than in the tubers, under both experimental conditions. Also, the OA variation on average is higher in tubers than in the shoots. On average, the OA in tubers and shoots increased, respectively, from 11 to $14 \mathrm{mg} 100 \mathrm{~g}^{-1}$

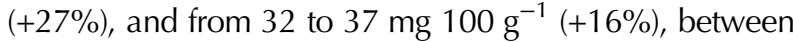
control and drought stress. However, in the acc. 1038, the OA content decreased to the same extend in both organs, clocking the same response to drought at $4 \mathrm{mg} 100 \mathrm{~g}^{-1}$. Inversely, acc. 1036, 2927, 3126 and 2937 increased the OA content in both organs under both conditions. The acc. 1036 showed significantly higher OA content, reach-

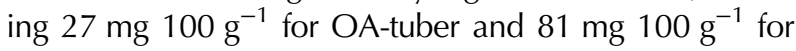
OA-shoot under water scarcity conditions.

\section{WUE and $\mathrm{CCl}$ content variation to drought}

Data regarding the whole-plant WUE and the CCI from shoots are presented in Table 2. On average, drought led to a $60 \%$ increase of WUE, from 5 to $8 \mathrm{~g} \mathrm{I}^{-1}$. The acc. 1038 showed significantly higher WUE $\left(9.34 \mathrm{~g} \mathrm{I}^{-1}\right)$ under control conditions. The acc. 3124 exhibited the highest WUE range, from 5 to $17 \mathrm{~g} \mathrm{I}^{-1}$ (+240\%) under drought. Contrariwise, acc. 2937 had the lowest WUE 


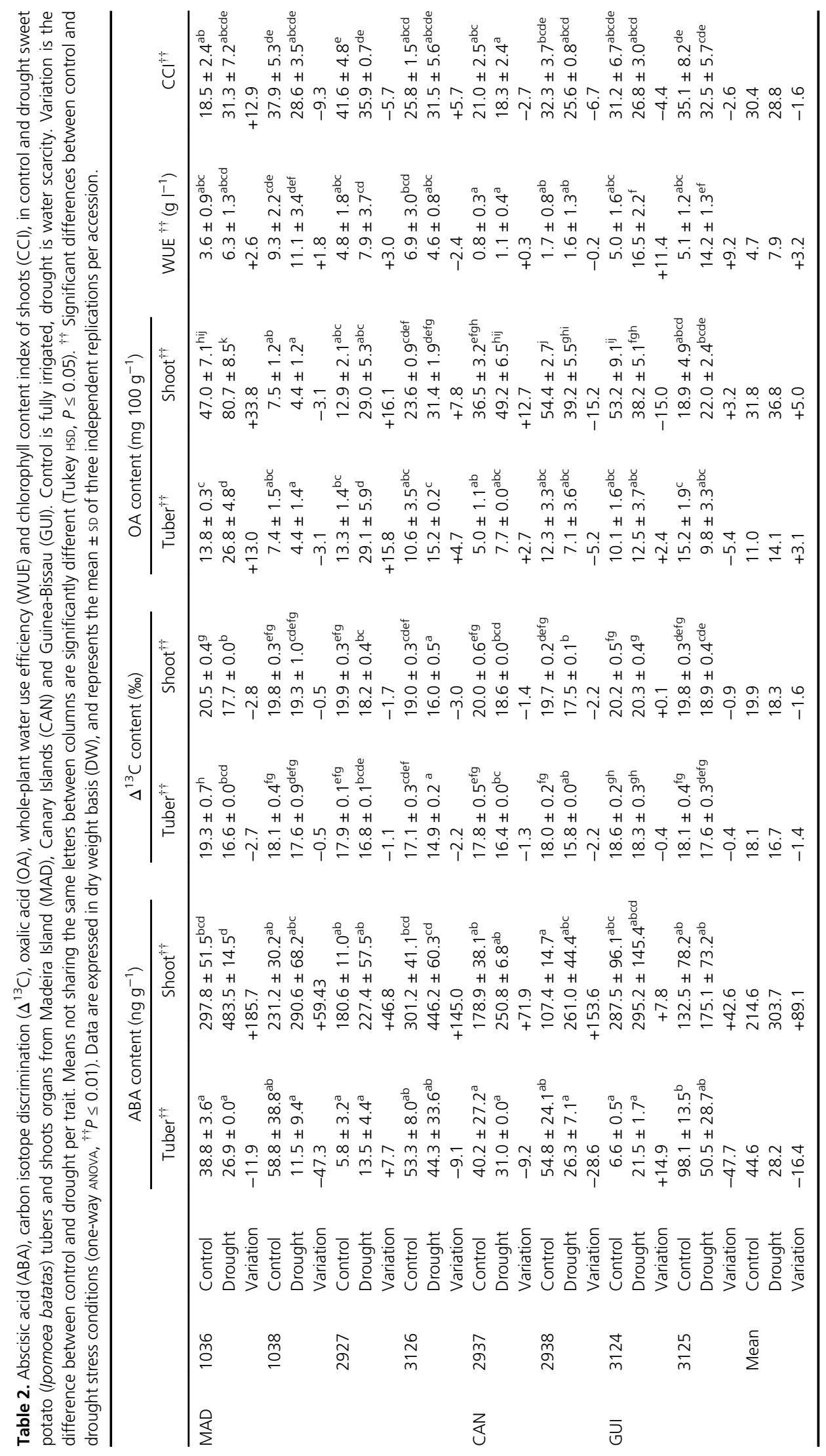


Table 3. Sweet potato (Ipomoea batatas) tubers and shoots Pearson correlation coefficients for WUE (whole-plant water use efficiency, $g \mathrm{I}^{-1}$ ), ABA (abscisic acid, $\mathrm{ng} \mathrm{g}^{-1}$ ), OA (oxalic acid, mg $100 \mathrm{~g}^{-1}$ ), $\Delta^{13} \mathrm{C}$ (carbon isotope discrimination, \%) and $\mathrm{CCl}$ (chlorophyll content index of shoots), for control and drought stress conditions. ** correlation is significant at the 0.01 level (2-tailed), *correlation is significant at the 0.05 level (2-tailed).

\begin{tabular}{|c|c|c|c|c|c|c|c|}
\hline & 1 & 2 & 3 & 4 & 5 & 6 & 7 \\
\hline 1. WUE & - & & & & & & \\
\hline 2. ABA-tuber & -0.11 & - & & & & & \\
\hline 3. OA-tuber & -0.12 & -0.09 & - & & & & \\
\hline 4. $\Delta^{13} \mathrm{C}$-tuber & 0.23 & 0.03 & -0.19 & - & & & \\
\hline 5. $\mathrm{CCl}$ & 0.24 & -0.04 & $0.32^{*}$ & 0.01 & - & & \\
\hline 6. ABA-shoot & 0.07 & $-0.30^{*}$ & 0.26 & $-0.40^{\star \star}$ & -0.12 & - & \\
\hline 7. OA-shoot & $-0.33^{*}$ & -0.15 & $0.39^{* *}$ & -0.08 & -0.28 & $0.36^{*}$ & - \\
\hline 8. $\Delta^{13} \mathrm{C}$-shoot & 0.15 & 0.01 & $-0.32^{*}$ & $0.92^{* *}$ & -0.06 & $-0.45^{* *}$ & -0.15 \\
\hline
\end{tabular}

under both experimental environments, ranging between 0.77 and $1.09 \mathrm{~g} \mathrm{I}^{-1}$ (+42\%). Meanwhile, acc. 3126 and 2938 were the only ones that decreased WUE under drought conditions.

Drought decreased the $\mathrm{CCl}$ by $3 \%$ on average, from 30 to 29 . The acc. 1036 and 3126 were the only ones that increased the $\mathrm{CCl}$ during drought, from 19 to $31(+63 \%)$ and 26 to $32(+23 \%)$, respectively. However, acc. 2927, 3124 and 3125 decreased the $\mathrm{CCl}$ under drought, but they managed to keep the highest chlorophyll content under both experimental conditions. Accession 1038 recorded the highest $\mathrm{CCl}$ decrease under drought, from 38 to $29(-24 \%)$, meanwhile acc. 2937 showed the smallest $\mathrm{CCl}$ among all accessions, ranging from 21 to $18(-14 \%)$.

\section{Variance and parameters associations}

Significant differences $(P \leq 0.01)$ were recorded between the eight sweet potato accessions (cases) by the one-way ANOVA and Tukey HSD multiple comparisons between control and drought environments for $\mathrm{ABA}, \mathrm{CCl}, \Delta^{13} \mathrm{C}$, $\mathrm{OA}$ and WUE (Table 2). Nine significant correlations $(P \leq 0.05)$ were detected among the five variables in the study, using the Pearson correlation coefficient (Table 3). One strong significant correlation was observed between $\Delta{ }^{13} \mathrm{C}$-shoot and $\Delta{ }^{13} \mathrm{C}$-tuber $(r=0.92)$. Modest correlations were registered between $\mathrm{ABA}$-shoot with $\Delta^{13} \mathrm{C}$-shoot $(r=-0.45), \Delta^{13} \mathrm{C}$-tuber $(r=-0.40)$, OA-shoot $(r=0.36)$ and with ABA-tuber $(r=-0.30)$. Other moderate correlations between OA-shoot with OA-tuber $(r=0.39)$ and WUE $(r=-0.33)$ were also detected. Similarly, the OAtuber with $\mathrm{CCl}(r=0.32)$ and with $\Delta{ }^{13} \mathrm{C}$-shoot $(r=-0.32)$ were moderately correlated.

The data from cases (samples) and variables (traits) were transformed into linearly uncorrelated variables through a PCA (Fig. 1). The PCA analysis explained $84.4 \%$ of total cumulative variance along with four principal components, i.e. axis. The first two axis explained $54.6 \%$ of the cumulative variance. The axis 1 had $34.1 \%$ of variance with eigenvalues of 2.7 , while the axis 2 had $20.5 \%$ of variance with eigenvalues of 1.6 . The

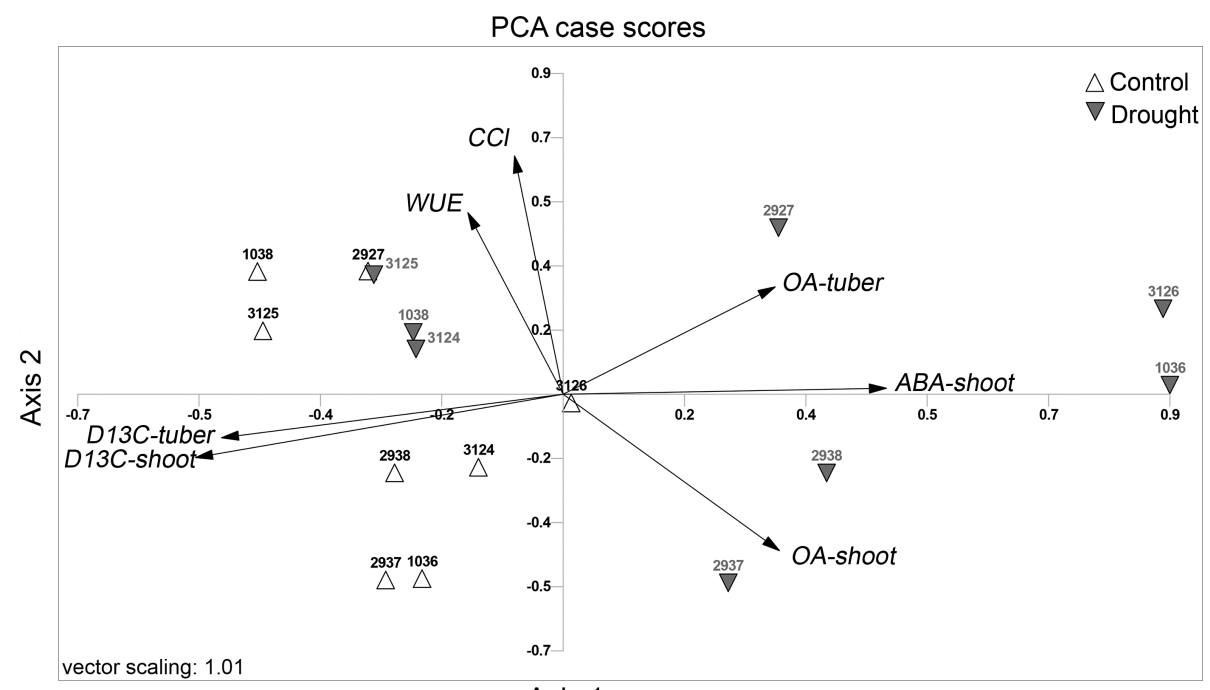

Axis 1
Fig. 1. Euclidean biplot with variables (ABA, CCl, $\Delta^{13} \mathrm{C}, \mathrm{OA}$, WUE) spatial distribution of the root tubers and shoots case scores from sweet potato accessions, using the principal component analysis (PCA). All the variables were converted by $\log _{\mathrm{e}}$. Control is fully irrigated; drought is water scarcity. 
ABA-shoot, $\Delta^{13} \mathrm{C}$-shoot and $\Delta^{13} \mathrm{C}$-tuber were the main variables that show a strong correlation relative to axis 1; meanwhile, the $\mathrm{CCl}$ and WUE variables were highly correlated with axis 2 . The accessions spatially distributed near to the end of the main variable vectors, as referred above for both axis, are the ones with the highest variability. When the main variable vectors are in opposed directions, it can show a reverse relation between them. For example, the drought-stressed acc. 1036 and 3126 were situated at the end of the ABA-shoot variable vector, which was in the opposed direction relative to the $\Delta^{13} \mathrm{C}$-shoot and $\Delta^{13} \mathrm{C}$-tuber vectors. It showed that their spatial distribution associated them, among all acc., as the ones with the highest ABA-shoot, and with the lowest $\Delta{ }^{13} \mathrm{C}$-shoot and $\Delta{ }^{13} \mathrm{C}$-tuber for drought conditions. As both accessions showed the highest spatial distance between the control and drought variants, they apparently also denoted the highest sensitivity to drought. On the other hand, acc. 3124, 3125 and 1038 shared practically the same spatial distribution between control and drought environments, displaying a more efficient response to drought.

\section{Discussion}

\section{ABA-shoot and ABA-tuber interaction at drought}

ABA naturally accumulates during plant growth and its accumulation is enhanced under stress conditions (Nakatani and Komeichi 1991). When plants experience water scarcity, they respond with ABA-shoot accumulation by initiating an adaptive response through the regulation of the plant water status as a strategy to survive under the hostile conditions (McAdam et al. 2016). In fact, we observed an ABA-shoot accumulation in all accessions tested in our study.

Under control conditions, the content of ABA-shoot was approximately fivefold higher than ABA-tuber, which agrees with $\mathrm{Li}$ and Jia (2014) findings. These authors argued that under stress-free conditions, plant leaves usually show a much higher $\mathrm{ABA}$ content than the roots and stems, due to a higher ABA content located in the chloroplasts (up to $68 \%$ of total $A B A$ ). The 5 -fold difference registered between the shoot and tuber organs increased up to 11-fold under drought stress. This increase could be attributed to the general ABA accumulation in sweet potato shoots in detriment to the decrease of $A B A$ in tubers as a response to drought. In case the underground organs are unable to synthesize ABA during drought conditions, either because of biochemical inability or collapse of carotenoid precursor reserves ( $\beta$-carotene), it was found that plants could have a normal increase in foliar $A B A$ level, with normal stomatal responses to drought (Danquah et al. 2013, McAdam et al. 2016). The significant negative correlation between $\mathrm{ABA}$ in both organs allow us to corroborate the presence of a root-toshoot ABA signaling path in sweet potato during water privation (Mengel et al. 2001, Osakabe et al. 2014, Salehi-Lisar and Bakhshayeshan-Agdam 2016). The drought is signalized to the shoots, where the signal is amplified in the leaf chloroplasts to accumulate ABA (Mengel et al. 2001, Osakabe et al. 2014, McAdam et al. 2016, Salehi-Lisar and Bakhshayeshan-Agdam 2016, Wani et al. 2016). However, the increase of the ABA-shoot biosynthesis can lead to a higher ABA catabolism due to the depletion of the ABA xanthophyll precursors. Drought may compromise the delivery of $\mathrm{ABA}$ precursors from the shoots to the roots, which could be one of the reasons for the decrease of ABA-tubers content (Li and Jia 2014, McAdam et al. 2016). We reported that only two accessions (2927 and 3124) increased the ABA-tuber during stress. This suggests that both exhibit a dynamic equilibrium between ABA biosynthesis and catabolism, which remains in agreement with the conclusions of $\mathrm{Li}$ and Jia (2014). Taking into consideration reports of Duman (2012) and Tuberosa (2012), we hypothesize that the ABA-tuber increase in acc. 2927 and 3124 could have facilitated the plant water uptake into the roots during drought, which also led to a better diffusion of nutrients taken from the soil into the plant. Such a pattern of response to drought was not present in the remaining accessions which show a decreased ABA-tuber content. However, the increasing levels of $A B A$ in maize roots during drought conditions stimulated root elongation and hence facilitated the pursuit of water and nutrients in surrounding soil environments (Sah et al. 2016). However, our observations do not support Sah et al. (2016) findings in maize plants, since the reduction of sweet potato total biomass appeared to be a way for them to cope with water stress (Gouveia et al. 2019). Likewise, Lau et al. (2018) observed a downregulation of tissue growth with higher $A B A$ accumulation in in vitro sweet potato plantlets. Jarret and Gawel (1991) also demonstrated that sweet potato plantlets exposed to four concentrations of $A B A$, ranging from 0.01 to $10 \mathrm{mg} \mathrm{l}^{-1}$ (i.e. 10-10 $000 \mathrm{ng} \mathrm{g}^{-1}$ ), had lag development of root and axillary buds from nodal segments. Considering that we dealt with fully grown tubers and shoots that were subjected to a long water scarcity period, the ABA values naturally varied among the accessions and their organs. Although, the highest $A B A$ values obtained for the shoots (484 $\mathrm{ng} \mathrm{g}^{-1}$ for acc. 1036) and for tubers (51 $\mathrm{ng} \mathrm{g}^{-1}$ for acc. 3125) under drought were not significantly correlated with the total plant biomass loss (data not shown). The ABA accumulation in response to water scarcity stress ought to be considered merely a conjecture of the mechanism of plants' resilience to water stress. We incline to hypothesize that $A B A$ was 
predominantly involved in the regulation of plant water status in association with the other traits investigated in this study rather than playing a direct role in the downregulation of tissue growth during drought. However, our results also show that ABA evolvement depends on accessions skills, because they demonstrated to have differentiated behavior under drought.

\section{ABA variation and its relationship with other drought tolerance traits}

$A B A$ modulates the plant responses including the regulation of stomatal opening, growth and development, and contributes to the stress signal transduction pathways during drought (Ramakrishna and Ravishankar 2014). Under normal conditions of ample water availability, stable ABA content delays leaf senescence and allows cumulative photosynthesis and transpiration processes over the crop cycle (Tardieu and Davies 1992, Tuberosa 2012, Osakabe et al. 2014). Open stomata allows higher photosynthesis activity and higher $\mathrm{CCl}$ content, which improves the carboxylation fractionation due to an equilibrate $\mathrm{CO}_{2}$ diffusion in leaf chloroplasts, with $\Delta^{13} \mathrm{C}$ values reaching near $31 \%$ or $\delta^{13} \mathrm{C}=-38 \%$; O'Leary 1993, Osakabe et al. 2014, Shao et al. 2015). The higher the plant transpiration, the greater is the water potential gradient between the root tubers and shoot cells. The scarce water availability in the roots reduces the water status in shoots, i.e. the $A B A$ increased content in the leaves induces stomata closure to reduce transpiration as a water-conserving mechanism (Tardieu and Davies 1992, Osakabe et al. 2014). Reduced transpiration rates compromise nutrient transport from the roots to the shoots, while nutrient stress could be another possible factor stimulating the accumulation of ABA (Firon et al. 2009, Duman 2012). Lower transpiration reduces water loss and leads to WUE increase (Black et al. 2015). Nonetheless, the stomatal closure restricts the photosynthetic activity and constrains the leaf $\mathrm{CO}_{2}$ uptake, which leads to a decrease of carboxylation fractionation and drives to $\Delta^{13} \mathrm{C}$ values near to $4 \%$ (or $\delta^{13} \mathrm{C}=-12 \%$; O'Leary 1993).

We observed that the ABA-shoot increase was significantly correlated with $\Delta^{13} \mathrm{C}$-tuber decrease, and both factors were connected to stomatal closure. The available data of $\Delta{ }^{13} \mathrm{C}, \mathrm{CCl}$, and WUE point to a partial closure of the stomata in sweet potato as a response to drought. Lau et al. (2018) also showed that in vitro sweet potato plantlets registered an ABA level increment during drought, leading to stomatal closure to avoid water loss by transpiration. The $\mathrm{CCl}$ decrease could indicate that drought slightly restricted the sweet potato photosynthesis activity, while the $\Delta^{13} \mathrm{C}$ decrease indicates that the carboxylation fractionation was lowered due to lower leaf $\mathrm{CO}_{2}$ availability (Farquhar et al. 1989, O'Leary 1993, Shao et al. 2015, Zhang et al. 2015, Gouveia et al. 2019). Both organs decreased $\Delta^{13} \mathrm{C}$ due to drought, with the amount of $\Delta^{13} \mathrm{C}$-shoot slightly greater than $\Delta^{13} \mathrm{C}$-tuber in both control and drought conditions, which was also observed by Zhang et al. (2015). This indicates that the $\Delta{ }^{13} \mathrm{C}$-tuber still had a greater ${ }^{13} \mathrm{C}$ fixation relatively to $\Delta{ }^{13} \mathrm{C}$-shoot as a result of the transport of photoassimilates from shoots to tubers, which improved plant growth during drought stress (Wegener et al. 2015, Zhang et al. 2015).

The partial closure of stomata could be also connected to the increment of oxalic acid, affecting the ABA signal to induce stomatal closure. With the increase of oxalic acid content, the shoot accumulates osmotically active molecules that induce the stomatal opening instead of closing it as signaled by ABA (Guimarães and Stotz 2004). We found that OA-shoot increased during drought, which was significantly correlated with ABA-shoot accumulation. It may suggest that the ABA capacity to induce stomata closure was affected. The biosynthesis of OA organic osmolytes is the key for plant resistance to drought, helping to resist prolonged harsh water scarcity and permitting a better recovery upon rehydration (Tuberosa 2012). Plant accumulation of OA occurs from the glycolate oxidized in glyoxylate derived from photosynthesis activity, which is then oxidized into oxalic acid (Igamberdiev and Eprintsev 2016). However, drought slightly downregulated photosynthesis due to the CCI decrease, perchance to protect the chloroplasts from photoinhibition and subsequent oxidative damage (Prasad et al. 2008, van Heerdena and Laurie 2008, Osakabe et al. 2014). Nonetheless, the partial stomatal closure still allowed for reasonably high $\mathrm{CCl}$ and organic osmolytes synthesis and permitted the increase of WUE during drought to minimize biomass loss.

The plants that were the most resilient to drought had greater ABA-shoot production, higher photosynthesis activity, higher chlorophyll content and increased WUE (Tardieu and Davies 1992, Tuberosa 2012, Black et al. 2015, Lau et al. 2018). Taking into consideration all studied traits, the acc. 3124 could be considered the most resilient to drought, followed by accessions 3125 and 1038. The acc. 3124 managed to retain high CCI content and a good carboxylation fractionation resulting from an equilibrate $\mathrm{CO}_{2}$ diffusion in leaf chloroplasts, with minimal $\Delta^{13} \mathrm{C}$ difference. This may point to a good photosynthesis rate under both experimental conditions. This acc. also had the highest $\Delta^{13} \mathrm{C}$-tuber content, an indicator of efficient tuber ${ }^{13} \mathrm{C}$ fixation and growth during drought. It maintained a balanced OA equilibrium in both organs and showed the best WUE under both experimental conditions. Finally, a high $\mathrm{ABA}$ production 
sustains in both organs in response to stress, allowing for a better osmotic and nutrient equilibrium.

\section{Conclusions}

Using multivariate analysis, analysis of variance and correlations, it was shown how the differences of ABA content in eight sweet potato accessions grown under water scarcity were related to the $\mathrm{CCl}, \Delta^{13} \mathrm{C}$, OA and WUE. Drought triggered ABA-shoots biosynthesis, while it significantly decreased the ABA-tubers content. The ABAshoot accumulation was correlated with $\Delta^{13} \mathrm{C}$-shoot and $\mathrm{OA}$ decrease. The ABA-shoot increase seemed to be a root-to-shoot $A B A$ signaling attempt to cope with water stress by stomatal closure, which was directly related to the $\Delta^{13} \mathrm{C}$ and $\mathrm{CCl}$ decrease, and higher WUE. The presence of OA-shoot may have affected the intensity of the ABA-shoot signal in stomatal closure, contributing to only a partial stomatal closure during the harsh water scarcity conditions. These combined factors appeared to be suitable tools to identify sweet potato accessions with higher resilience to drought. Among all accessions in the study, acc. 3124 exhibited the best trait combination in response to water scarcity. Therefore, it should be considered as a potential candidate for sweet potato drought tolerance improvement programs, that can be used in culture adaptation to climate changes.

\section{Author contributions}

C.G. participated to the drought assay and samples preparation, performed the ABA and oxalic analysis, interpreted and summarized all data generated from those experiments, and wrote the manuscript. J.G. quantified the WUE and helped C.G. in CCI. J.S. coordinated the $\delta^{13} \mathrm{C}$ analysis. V.L. and M.C. coordinated the work and revised the manuscript.

Acknowledgements - The authors thank J.G.R. de Freitas and H.G.M. de Nóbrega from the ISOPlexis Genebank from the Madeira University (Portugal) who provided valuable assistance with the management of the field trials and meaningfully contributed to the harvest and samples preparation. This work was supported by the Programa Operacional Madeira 14-20, Portugal 2020 and the European Union through the European Regional Development Fund (grant number M1420-01-0145-FEDER-000011, CASBio), and Agência Regional para o Desenvolvimento da Investigação Tecnologia e Inovação, Portugal 2020 and the European Union through the European Social Fund (grant number M1420-09-5369-FSE-000001, ARDITI).

\section{Data availability statement}

The data that support the findings of this study are available from the corresponding author upon reasonable request.

\section{References}

AOAC (2000) Micro-chemical determination of carbon, hydrogen, and nitrogen, automated method, method 972.43. In: Horwitz W (ed) Official Methods of Analysis, 17th Edn. AOAC International Publisher, Arlington, TX

Black CR, Randhawa D, Ong CK (2015) Principles of resource capture and use of light and water. In: Ong CK, Black CR, Wilson J (eds) Tree-Crop Interactions: Agroforestry in a Changing Climate. CABI, Wallingford, pp 73

Bradbury JH, Holloway WD (1988) Chemistry of tropical root crops: significance for nutrition and agriculture in the Pacific. ACIAR Monograph No. 6. Australian Centre for International Agricultural Research, Canberra, pp 18,160

Danquah A, de Zelicourt A, Colcombet J, Hirt H (2013) The role of $A B A$ and MAPK signaling pathways in plant abiotic stress responses. Biotechnol Adv 32: 40-52

Duman F (2012) Uptake of mineral elements during abiotic stress. In: Ahmad P, Prasad MNV (eds) Abiotic Stress Responses in Plants: Metabolism, Productivity and Sustainability. Springer, New York, pp 270-271

Dye WB (1956) Chemical studies on Halogeton glomeratus. Weeds 1: 55-60

Ekanayake IJ, Collins W (2004) Effect of irrigation on sweet potato root carbohydrates and nitrogenous compounds.

J Food Agric Environ 2: 243-248

FAOSTAT Statistical Database (2018). Food and Agriculture Organization of the United Nations, FAO, Rome. Available at http://www.fao.org/faostat/en/?\#data/QC (accessed 30 July 2020)

Farquhar GD, Ehleringer JR, Hubidk KT (1989) Carbon isotope discrimination and photosynthesis. Annu Rev Plant Physiol 40: 503-537

Firon N, LaBonte D, Villordon A, McGregor C, Kfir Y, Pressman E (2009) Botany and physiology: Storage root formation and development. In: Loebenstein G, Thottappilly G (eds) The Sweetpotato. Springer, Dordrecht, pp 18-19, 23

Franceschi VR and Horner HT (1980) Calcium oxalate crystals in plants. Bot Rev 46: 361-427.

Ganança JFT, Freitas JGR, Nóbrega HGM, Rodrigues V, Antunes G, Gouveia CSS, Rodrigues M, Chaïr H, Pinheiro de Carvalho MÂA, Lebot V (2018) Screening for drought tolerance in thirty three taro cultivars. Not Bot Horti Agrobot Cluj-Napoca 46: 65-74

Gouveia CSS, Ganança JFT, Slaski J, Lebot V, Pinheiro de Carvalho MÂA (2019) Variation of carbon and isotope 
natural abundances $\left(\delta^{15} \mathrm{~N}\right.$ and $\left.\delta^{13} \mathrm{C}\right)$ of whole-plant sweet potato (Ipomoea batatas L.) subjected to prolonged water stress. J Plant Physiol 243: 153052

Gouveia CSS, Ganança JFT, Lebot V, Pinheiro de Carvalho MÂA (2020) Changes in oxalate composition and other nutritive traits in root tubers and shoots of sweet potato (Ipomoea batatas L. [Lam.]) under water stress. J Sci Food Agr 100: 1702-1710

Guimarães RL, Stotz HU (2004) Oxalate production by Sclerotinia sclerotiorum deregulates guard cells during infection. Plant Physiol 136: 3703-3711

van Heerdena PDR, Laurie R (2008) Effects of prolonged restriction in water supply on photosynthesis, shoot development and storage root yield in sweet potato. Physiol Plant 134: 99-109

Huang Z, Kabir MH, Xiao Y, Liu Q, Tong J, Xiao L (2014) Principles and practice of ABA analysis. In: Zhang D-P (ed) Abscisic Acid: Metabolism, Transport and Signaling, Vol. 431. Springer, Dordrecht, pp 436-438

Igamberdiev AU, Eprintsev AT (2016) Organic acids: the pools of fixed carbon involved in redox regulation and energy balance in higher plants. Front Plant Sci 7: 1042

Ishida H, Suzuno H, Sugiyama N, Innami S, Tadokoro T, Maekawa A (2000) Nutritive evaluation on chemical components of leaves, stalks and stems of sweet potatoes (Ipomoea batatas poir). Food Chem 68: 359-367

Jarret R, Gawel N (1991) Abscisic acid-induced growth inhibition of sweet potato (Ipomoea batatas L.) in vitro. Plant Cell Tiss Org 24: 13-18

Lau KH, Herrera MR, Crisovan E, Wu S, Fei Z, Khan MA, Buell CR, Gemenet DC (2018) Transcriptomic analysis of sweet potato under dehydration stress identifies candidate genes for drought tolerance. Plant Direct 2: 1

Lebot V (2009)In: Atherton J, Rees A (eds) Tropical Root and Tuber Crops: Cassava, Sweet Potato, Yams and Aroids, Vol. 97. CAB International, Cambridge, pp 167

$\mathrm{Li} \mathrm{B}$, Jia W (2014) ABA content in relation to ABA biosynthesis and catabolism. In: Zhang D-P (ed) Abscisic Acid: Metabolism, Transport and Signaling. Springer, Dordrecht, pp 62, 64

Ma Y, Qin F (2014) ABA regulation of plant responses to drought and salt stresses. In: Zhang D-P (ed) Abscisic Acid: Metabolism, Transport and Signaling. Springer,

Dordrecht, pp 315, 324

McAdam SAM, Manzi M, Ross JJ, Brodribb TJ, GómezCadenas A (2016) Uprooting an abscisic acid paradigm: shoots are the primary source. Plant Signal Behav 11: e1169359

Mengel K, Kirkby EA, Kosegarten H, Appel T (2001) Principles of Plant Nutrition. Springer, the Netherlands, pp 222-225, 265-276

Motsa NM, Modi AT, Mabhaudhi T (2015a) Sweet potato response to low-input agriculture and varying environments of KwaZulu-Natal, South Africa: implications for food security strategies. Acta Agr Scand B-S P 65: 329-340

Motsa NM, Modi AT, Mabhaudhi T (2015b) Sweet potato (Ipomoea batatas L.) as a drought tolerant and food security crop. S Afr J Sci 111: 1-8

Nagata T, Saitou K (2009) Regulation of expression of D3-type cyclins and ADP-glucose pyrophosphorylase genes by sugar, cytokinin and ABA in sweet potato (Ipomoea batatas lam.). Plant Prod Sci 12: 434-442

Nakatani M, Komeichi M (1991) Changes in the endogenous level of zeatin riboside, abscisic acid and indole acetic acid during formation and thickening of tuberous roots in sweet potato. Japan J Crop Sci 60: 91-100

O'Leary MH (1993) Biochemical basis of carbon isotope fractionation. In: Ehleringer JR, Hall AE, Farquhar GD (eds) Stable Isotopes and Plant Carbon-Water Relations. Academic Press Inc, California, pp 19-26

Osakabe Y, Osakabe K, Shinozaki K (2014) Plant environmental stress responses for survival and biomass enhancement. In: Tuteja N, Gill SS (eds) Climate Change and Plant Abiotic Stress Tolerance. Wiley-Blackwell, Germany, pp 82-86

Prasad PVV, Staggenborg SA, Ristic Z (2008) Impacts of drought and/or heat stress on physiological, developmental, growth, and yield processes of crop plants. In: Ahuja LR, Reddy VR, Saseendran SA, Qiang Y (eds) Response of Crops to Limited Water: Understanding and Modeling Water Stress Effects on Plant Growth Processes. American Society of Agronomy, Crop Science Society of America, Soil Science Society of America, USA, pp 304-308

Ramakrishna A, Ravishankar GA (2014) Role of plant metabolites in abiotic stress tolerance under changing climatic conditions with special reference to secondary compounds. In: Tuteja N, Gill SS (eds) Climate Change and Plant Abiotic Stress Tolerance. Wiley-Blackwell, Germany, pp 712

Ravi V, Saravanan R (2012) Crop physiology of sweet potato. Fruit Veg Cereal Sci Biotech 6: 17-29

Van Reeuwijk LP, Houba VJG, Food and Agriculture Organization of the United Nations, International Soil Reference and Infor- mation Centre (1998) Guidelines for quality management in soil and plant laboratories, Vol 222, 74th edn. Food and Agriculture Organization of the United Nations, International Soil Reference and Information Centre, Rome (ISSN 0253-2050)

Saddhe AA, Kundan K, Padmanabh D (2017) Mechanism of ABA signaling in response to abiotic stress in plants. In: Pandey GK (ed) Mechanism of Plant Hormone Signaling Under Stress, Chapter, Vol. 8. John Wiley \& Sons Inc, New Jersey, pp 173

Sah SK, Reddy KR, Li J (2016) Abscisic acid and abiotic stress tolerance in crop plants. Front Plant Sci 7: 571

Salehi-Lisar SY, Bakhshayeshan-Agdam H (2016) Drought stress in plants: Causes, consequences and tolerance. In: Hossain MA, Wani SH, Bhattacharjee S, Burritt DJ, 
L-SP T (eds) Drought Stress Tolerance in PlantsPhysiology and Biochemistry, Vol. 1. Springer, Switzerland, pp 1-17

Shao G, Yuan M, Liu N, Ji J, Yu W (2015) Effect of rain shelters and drought on leaf water status and photosynthetic parameters in tomato. Arch Agron Soil Sci 61: 1273-1288

Smittle DA, Hall MR, Stansell JR (1990) Effects of irrigation regimes on yield and water use by sweet potato. J Am Soc Hortic Sci 115: 712-714

Tardieu F, Davies WJ (1992) Stomatal response to abscisic acid is a function of current plant water status. Plant Physiol 98: 540-545

Tuberosa R (2012) Phenotyping for drought tolerance of crops in the genomics era. Front Physiol 3: 347

Vishwakarma K, Upadhyay N, Kumar N, Yadav G, Singh J, Mishra RK, Kumar V, Verma R, Upadhyay RG, Pandey M, Sharma S (2017) Abscisic acid signaling and abiotic stress tolerance in plants: a review on current knowledge and future prospects. Front Plant Sci 8: 161

Wang Y, Frei M (2011) Stressed food - the impact of abiotic environmental stresses on crop quality. Agric Ecosyst Environ 141: 271-286

Wani SH, Kumar V, Shriram V, Kumar S (2016) Phytohormones and their metabolic engineering for abiotic stress tolerance in crop plants. Crop J 4: 162-176

Wegener F, Beyschlag W, Werner C (2015) Dynamic carbon allocation into source and sink tissues determine withinplant differences in carbon isotope ratios. Funct Plant Biol 42: 620-629

Zhang H, Zhu L, Zhang C, Ning Y, Zhang Y (2015) Effect of water stress on dry mass accumulation and allocation in sweet potato based on stable isotope analysis. Can J Plant Sci 95: 263-271 